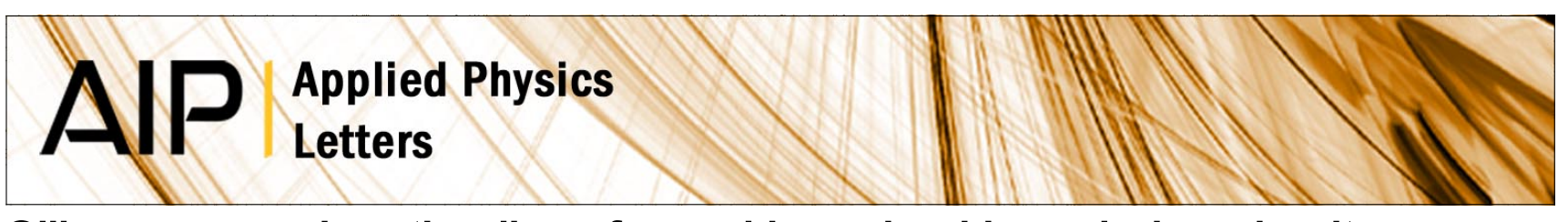

\title{
Silicon germanium tin alloys formed by pulsed laser induced epitaxy
}

S. Stefanov, J. C. Conde, A. Benedetti, C. Serra, J. Werner et al.

Citation: Appl. Phys. Lett. 100, 204102 (2012); doi: 10.1063/1.4714768

View online: http://dx.doi.org/10.1063/1.4714768

View Table of Contents: http://apl.aip.org/resource/1/APPLAB/v100/i20

Published by the American Institute of Physics.

Additional information on Appl. Phys. Lett.

Journal Homepage: http://apl.aip.org/

Journal Information: http://apl.aip.org/about/about_the_journal

Top downloads: http://apl.aip.org/features/most_downloaded

Information for Authors: http://apl.aip.org/authors

\section{ADVERTISEMENT}

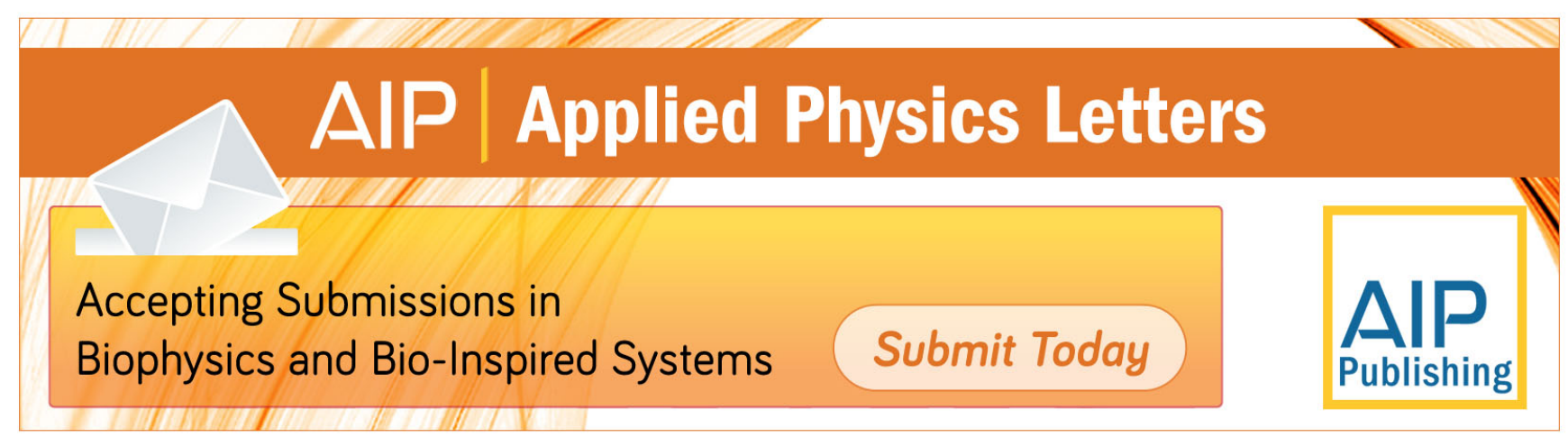




\title{
Silicon germanium tin alloys formed by pulsed laser induced epitaxy
}

\author{
S. Stefanov, ${ }^{1}$ J. C. Conde, ${ }^{1}$ A. Benedetti, ${ }^{2}$ C. Serra ${ }^{2}$ J. Werner, ${ }^{3}$ M. Oehme,${ }^{3}$ J. Schulze,${ }^{3}$ \\ D. Buca, ${ }^{4}$ B. Holländer, ${ }^{4}$ S. Mantl, ${ }^{4}$ and S. Chiussi ${ }^{1}$, a) \\ ${ }^{1}$ Dpto. Física Aplicada, Univ. de Vigo, Rua Maxwell s/n, Campus Universitario Lagoas Marcosende, \\ Vigo, Spain \\ ${ }^{2}$ CACTI, Univ. de Vigo, Campus Universitario Lagoas Marcosende 15, Vigo, Spain \\ ${ }^{3}$ Institut für Halbleitertechnik (IHT), Pfaffenwaldring 47, 70569 Stuttgart, Germany \\ ${ }^{4}$ Peter Grünberg Institute 9 (PGI 9-IT) and JARA-Fundamentals of Future Information Technologies, \\ Forschungszentrum Jülich, 52425 Jülich, Germany
}

(Received 13 March 2012; accepted 26 April 2012; published online 15 May 2012)

\begin{abstract}
Pulsed lased induced epitaxy is used to obtain heteroepitaxial $\mathrm{Ge}_{1-\mathrm{x}} \mathrm{Sn}_{\mathrm{x}}$ and $\mathrm{Si}_{1-\mathrm{x}-\mathrm{y}} \mathrm{Ge}_{\mathrm{x}} \mathrm{Sn}_{\mathrm{y}}$ alloys with graded composition on $\mathrm{Si}(001)$ substrates. The transition from $\mathrm{Ge}_{1-\mathrm{x}} \mathrm{Sn}_{\mathrm{x}}$ to $\mathrm{Si}_{1-\mathrm{x}-\mathrm{y}} \mathrm{Ge}_{\mathrm{x}} \mathrm{Sn}_{\mathrm{y}}$ was achieved by varying the number of laser pulses accordingly with the level of intermixing between $\mathrm{Si}, \mathrm{Ge}$, and $\mathrm{Sn}$. Melt duration, predicted by numerical methods, is experimentally confirmed by "in-situ" reflectivity measurements and relates, like the end reflectivity value, to the level of intermixing. The possibility to adjust concentration profiles through laser processing of $\mathrm{Sn}$ films on virtual germanium buffer layers for lattice engineering of $\mathrm{Ge}_{1-\mathrm{x}} \mathrm{Sn}_{\mathrm{x}}$ and $\mathrm{Si}_{1-\mathrm{x}-\mathrm{y}} \mathrm{Ge}_{\mathrm{x}} \mathrm{Sn}_{\mathrm{y}}$ alloys on silicon substrates is demonstrated. (c) 2012 American Institute of Physics. [http://dx.doi.org/10.1063/1.4714768]
\end{abstract}

In the last decade, large interest in extending $\mathrm{Si}_{1-\mathrm{x}} \mathrm{Ge}_{\mathrm{x}}$ based technology to $\mathrm{Ge}_{1-\mathrm{x}} \mathrm{Sn}_{\mathrm{x}}$ and $\mathrm{Si}_{1-\mathrm{x}-\mathrm{y}} \mathrm{Ge}_{\mathrm{x}} \mathrm{Sn}_{\mathrm{y}}$ alloys, as an innovative class of versatile semiconductors, has been shown. ${ }^{1-7}$ These Sn containing binary and ternary alloys can be used as active layers, via band gap tuning, or as structural buffers for the epitaxial integration of III/V compounds with silicon, thus to facilitate the convergence of Si based microelectronics and III/V photonics. ${ }^{4,7}$ Several studies to optimize traditional $^{8,9}$ and alternative ${ }^{10}$ epitaxial growth techniques have been started, particularly aiming to overcome the low solubility of $\mathrm{Sn}$ in $\mathrm{Ge}(<1 \%),{ }^{11}$ but also the large lattice mismatch of $4.2 \%$ and $19.6 \%$ between $\mathrm{Si}$ $\left(\mathrm{a}_{0}=0.5431 \mathrm{~nm}\right)$ and Ge $\left(\mathrm{a}_{0}=0.5658 \mathrm{~nm}\right)$ or $\alpha-\mathrm{Sn}$ $\left(\mathrm{a}_{0}=0.6493 \mathrm{~nm}\right)$, respectively. ${ }^{4}$

Pulsed laser induced epitaxy (PLIE) is an alternative growth technique ${ }^{12}$ that has already been used to produce high quality heteroepitaxial $\mathrm{Si}_{1-\mathrm{x}} \mathrm{Ge}_{\mathrm{x}}$ layers on $\mathrm{Si}$ with graded concentration profiles ${ }^{13,14}$ and might be effectively extended to $\mathrm{Ge}_{1-\mathrm{x}} \mathrm{Sn}_{\mathrm{x}}$ and $\mathrm{Si}_{1-\mathrm{x}-\mathrm{y}} \mathrm{Ge}_{\mathrm{x}} \mathrm{Sn}_{\mathrm{y}}$ alloys. ${ }^{15}$ The method features heat treatment in ultra-short time scale $(<500 \mathrm{~ns})$ and a reliable control of thermal gradients as well as stoichiometry, by varying laser energy density and laser pulses. ${ }^{16}$ Yet, little is known about how typical laser processing parameters are governing the synthesis of epitaxial $\mathrm{Ge}_{1-\mathrm{x}} \mathrm{Sn}_{\mathrm{x}}$ and $\mathrm{Si}_{1-\mathrm{x}-\mathrm{y}} \mathrm{Ge}_{\mathrm{x}} \mathrm{Sn}_{\mathrm{y}}$ alloys, ${ }^{12,13,17}$ thus detailed studies are needed for the further development of controlled PLIE processes.

In this paper, we examine the evolution of the intermixing between $\mathrm{Si}, \mathrm{Ge}$, and $\mathrm{Sn}$ upon laser irradiation and relate it to a theoretical model of the process. Changes in the vibrational and structural properties of the alloys achieved after different number of thermal cycles are systematically studied.

The laser treated sample consisted of a $100-110 \mathrm{~nm}$ thick virtual germanium (v-Ge) buffer, grown at $300^{\circ} \mathrm{C}$ through molecular beam epitaxy (MBE) in a single step pro-

${ }^{a)}$ Electronic mail: schiussi@uvigo.es. cess on $\mathrm{Si}(001)$, followed by the deposition of $4 \mathrm{~nm} \mathrm{Sn}$ at $85^{\circ} \mathrm{C}$, in the same reactor using an effusion cell. ${ }^{18}$ The samples were irradiated in $\mathrm{He}$ atmosphere using pulses of a commercial $193 \mathrm{~nm}$ ArF excimer laser. Pulse energy density was kept at $500 \mathrm{~mJ} / \mathrm{cm}^{2}$ and the number of laser pulses varied from 1 to 100 . The laser beam was spatially homogenized to a $4 \times 2 \mathrm{~mm}^{2}$ spot, while the energy density and the pulse width (25 ns FWHM) were "in-situ" measured, as described elsewhere. ${ }^{12}$

The laser pulses are absorbed very close to the surface of the structure (few nanometers below the Sn layer) and cause a molten pool, where at the beginning Sn and Ge and later Si are mixed with every consecutive pulse. ${ }^{13}$ The following rapid cooling of the melt leads to epitaxial recrystallization with the substrate acting as crystalline seed. Since melt duration depends on the thermal conductivity of the material, which is directly related to composition, ${ }^{19}$ this duration can be used as a control parameter ${ }^{20}$ and related to the level of intermixing. "In-situ" monitoring of the liquid phase duration was therefore performed, using time resolved reflectivity (TRR) measurements, as described elsewhere. ${ }^{12,20,21}$

The melt duration for the 1st pulse is obtained by solving the heat conduction differential equation (HCDE) using finite element methods. ${ }^{22}$ The simulation of subsequent pulses implies considering the formation of strong concentration gradients and of changes in composition, thus deviation of the thermal and optical material properties for each consecutive pulse. These deviations are generally difficult to simulate, but if the calculated data are in good agreement with the TRR ones for the 1st pulse, the validity of the simulation is experimentally confirmed. The combination of simulation and experimental TRR measurements might thus be applied as reliable tool to predict and control the level of intermixing for consecutive pulses.

The calculated surface and v-Ge/Si interface temperatures are presented in Fig. 1(a). A direct comparison with experimental data of the sample surface reflectivity change 

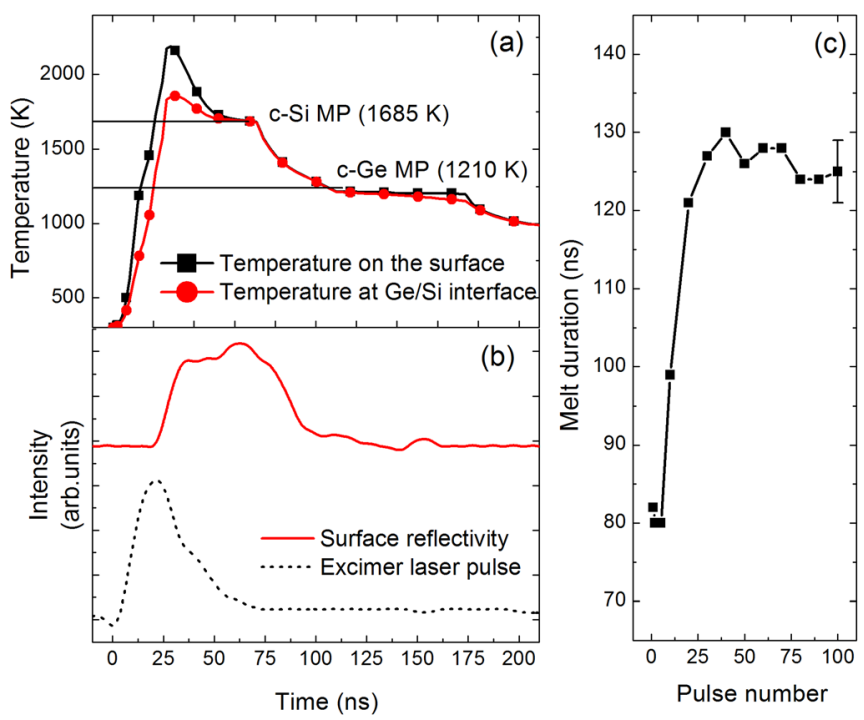

FIG. 1. (a) Calculated temporal evolution of the temperature at the surface and at the $\mathrm{v}-\mathrm{Ge} / \mathrm{Si}$ interface. The melting points (MP) for $\mathrm{c}-\mathrm{Si}$ and $\mathrm{c}-\mathrm{Ge}$ are marked; (b) "in-situ" measured sample reflectivity; (c) melt duration vs. number of laser pulses measured by surface reflectivity change (solid line is a guide to the eye).

(Fig. 1(b)), due to phase transition from solid to liquid, corroborates that melting starts, as predicted, at the maximum intensity of the laser pulse and lasts about $80 \mathrm{~ns}$. The calculated value for the liquid phase duration, without taking into account the composition change during the PLIE process, is about $98 \mathrm{~ns}$. Experimental data differ therefore from the model at the solidification tail, because the measured alloy should solidify faster than the simulated structure with the pure elements. ${ }^{19}$ Additional simulated data, valuable for adjusting the experimental parameters, are the maximum melting depth (about $200 \mathrm{~nm}$, as derived from the solution of the HCDE) and the temperature gradients at the surface and $\mathrm{Ge} / \mathrm{Si}$ interface (Fig. 1(a)).

Experimentally determined melt duration for the following pulses suggests a higher level of intermixing, while melt duration increases from around $80 \mathrm{~ns}$ at the 1 st pulse to about $130 \mathrm{~ns}$ at the 20th pulse (Fig. 1(c)). This is attributed to compositional changes, thus changes in the concentration depth profile. ${ }^{19}$ The almost constantly decreasing melt duration from the 20th to 100th laser pulse indicates a homogeneous profile or equilibrium in alloy concentration.

The structural and compositional changes, that affect the melt duration and the alloy formation, were studied by Raman spectroscopy. This non-destructive technique is well suited for analyzing composition and strain in SiGe (Ref. 9) and SiGeSn alloys. ${ }^{23}$ Figure 2(a) compares the Raman spectra, taken at $632.8 \mathrm{~nm}$ excitation, of the "as grown" (0 pulses) and $1,2,5,10$, and 100 pulses irradiated samples. A clear transition from $\mathrm{Ge}_{1-\mathrm{x}} \mathrm{Sn}_{\mathrm{x}}$ alloy (1 and 2 pulses) to $\mathrm{Si}_{1-\mathrm{x}-\mathrm{y}} \mathrm{Ge}_{\mathrm{x}} \mathrm{Sn}_{\mathrm{y}}$ alloy $(5,10$, and 100 pulses $)$ is observed. In the "as grown" sample, the Ge-Ge vibration mode from the $\mathrm{v}-\mathrm{Ge}$ layer at $301 \mathrm{~cm}^{-1}$ and the Si-Si mode from the Si substrate at $520.2 \mathrm{~cm}^{-1}$ are dominant, but also a weak peak around $385 \mathrm{~cm}^{-1}$ ascribed to $\mathrm{Si}$ impurities in the $\mathrm{v}-\mathrm{Ge}$ is present. The 1 and 2 pulses spectra reveal a transformation from $\mathrm{Ge}$ to $\mathrm{Ge}_{1-x} \mathrm{Sn}_{\mathrm{x}}$ with the typical shift of the Ge-Ge alloy vibration mode position below $301 \mathrm{~cm}^{-1}$ and the emer-

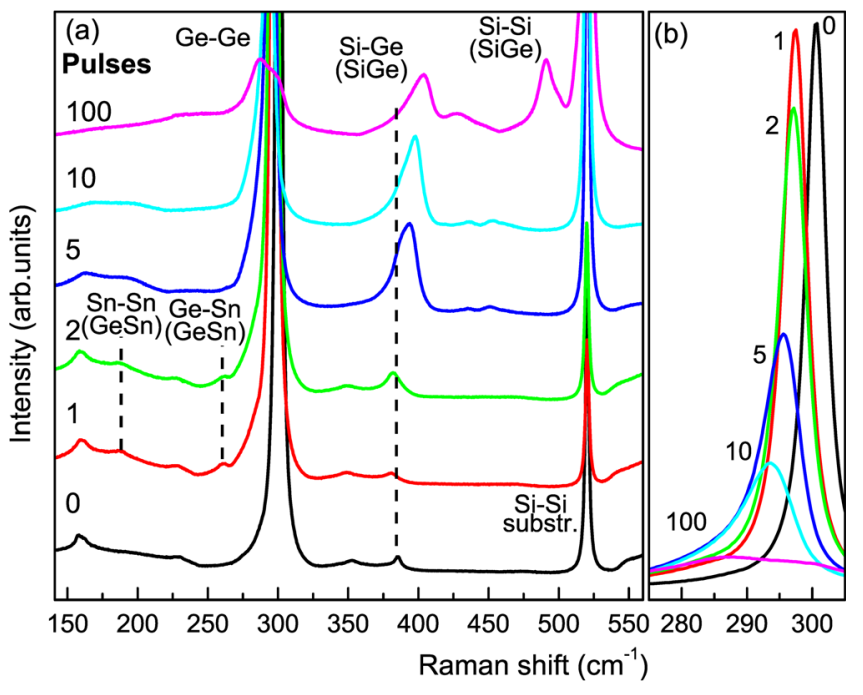

FIG. 2. Evolution of the Raman spectra with increasing number of pulses (a) (each spectrum is shifted vertically for clearer representation) and follow up of the Ge-Ge vibration mode (b). Numbers correspond to the number of laser pulses with shift from the pure Ge vibration $\Delta \omega_{\mathrm{Ge}-\mathrm{Ge}}$ of $-3,-3.3$, $-4.8,-6.6$, and $-14 \mathrm{~cm}^{-1}$ for $1,2,5,10$, and 100 pulses, respectively.

gence of the Ge-Sn mode at $262 \mathrm{~cm}^{-1} \cdot{ }^{24}$ As seen in the temporal temperature distribution (Fig. 1), the topmost $100 \mathrm{~nm}$ layer (Ge and $\mathrm{Sn}$ ) stays almost two times longer in the liquid phase than the Si from the Si substrate, thus leading to a homogenization of the Sn distribution in the Ge layer, whereas $\mathrm{Si}$ and Ge are only negligibly mixed. This is confirmed by the slightly increased intensity of the Si-Ge vibration of the 2 pulses spectrum. The samples irradiated with 5 and 10 pulses are an intermediate case between $\mathrm{Ge}_{1-\mathrm{x}} \mathrm{Sn}_{\mathrm{x}}$ and $\mathrm{Si}_{1-\mathrm{x}-\mathrm{y}} \mathrm{Ge}_{\mathrm{x}} \mathrm{Sn}_{\mathrm{y}}$, evidencing the promoted broader downshifted Ge-Ge vibrational mode of an $\mathrm{Ge}_{1-\mathrm{x}} \mathrm{Sn}_{\mathrm{x}}$ alloy (Fig. 2(b)). On the other hand, the Sn seems to be already highly diluted and the previously emerging Ge-Sn mode therefore no longer active. The increasing Si-Ge vibration intensity and the shift to higher wavenumbers reveal formation of $\mathrm{Si}_{1-\mathrm{x}} \mathrm{Ge}_{\mathrm{x}}$ alloys with higher $\mathrm{Si}$ content. The Raman spectrum of the alloy after 100 pulses, finally, evidences only $\mathrm{Si}_{1-\mathrm{x}} \mathrm{Ge}_{\mathrm{x}}$ characteristic features. The Ge-Ge mode is shifted to $287 \mathrm{~cm}^{-1}$ forming a broad peak together with the 2TA mode from the Si substrate at around $300 \mathrm{~cm}^{-1} .25$

Time of flight secondary ion mass spectrometry (TOFSIMS) depth profile delivers additional information on the distribution of the $\mathrm{Si} / \mathrm{Ge} / \mathrm{Sn}$ compounds in the alloy. Figure 3 compares the SIMS depth profiles acquired at negative polarity of the "as grown" and the 5 and 100 pulses samples. Starting from the 5 pulses irradiation which is the intermediate case according to the Raman measurement, the pulse dependent alloy intermixing becomes clear: $\mathrm{Sn}$ and $\mathrm{Ge}$ concentration gradients are formed toward the substrate, whereas a $\mathrm{Si}$ gradient is formed toward the surface. After 100 pulses, a $100 \mathrm{~nm}$ layer with constant $\mathrm{Si} / \mathrm{Ge}$ composition and strongly diluted $\mathrm{Sn}$ content on top of the graded $\mathrm{Si}_{1-\mathrm{x}} \mathrm{Ge}_{\mathrm{x}}$ layer is formed on the Si substrate.

Since formation of such composition gradients by rapid solidification might be used as a natural mechanism for lattice adjustment, a more detailed study of the microstructure is required. Lattice mismatch, if not properly compensated, can lead to high defect density and low crystal quality of the 


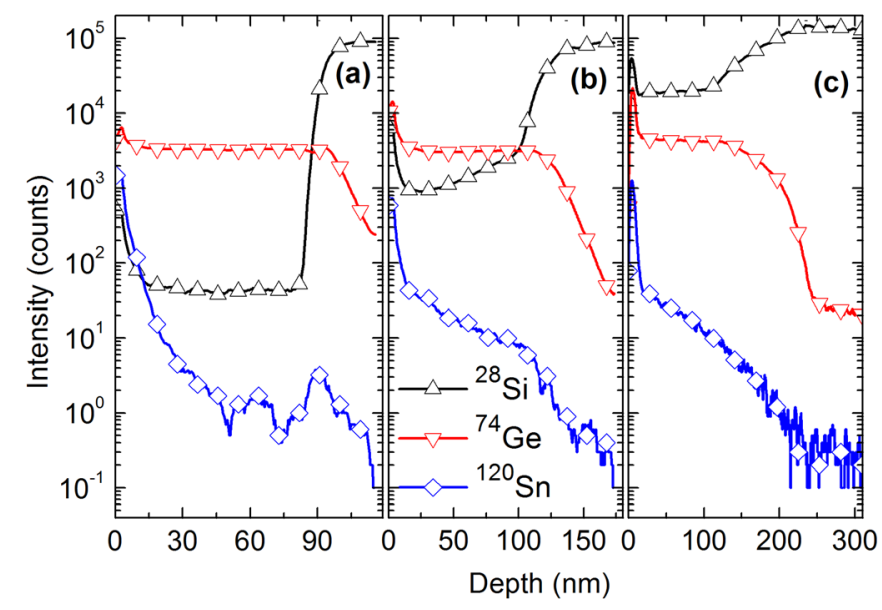

FIG. 3. TOF-SIMS depth profile of the sample (a) "as grown," (b) irradiated with 5 and (c) 100 pulses of $500 \mathrm{~mJ} / \mathrm{cm}^{2}$.

layer. Strain compensation by elements intermixing in a molten pool through PLIE has already been studied for $\mathrm{Si}_{1-\mathrm{x}} \mathrm{Ge}_{\mathrm{x}}$ alloys, and it has been shown that high crystal quality can be obtained, if processing parameters are well adjusted. ${ }^{13-16}$

Transmission electron microscopy (TEM) was employed for insights into the crystal quality. The "as grown" v-Ge, being grown as a single step virtual substrate, already possess a high amount of threading-dislocations (defect density $\left.>1 \times 10^{10} / \mathrm{cm}^{2}\right)^{18}$ (Fig. 4(a)). After 5 pulses, a two layer system is formed (Fig. 4(b)), with a top $\left(\mathrm{Si}_{1-\mathrm{x}-\mathrm{y}}\right) \mathrm{Ge}_{\mathrm{x}} \mathrm{Sn}_{\mathrm{y}}$ layer of graded $\mathrm{Si}$ content, according to the TOF-SIMS measurement, followed by an about $20 \mathrm{~nm}$ thick $\mathrm{Si}_{1-\mathrm{x}} \mathrm{Ge}_{\mathrm{x}}$ alloy. From the observed strain fields, we assume that this last layer is a PLIE formed strained $\mathrm{Si}_{1-\mathrm{x}} \mathrm{Ge}_{\mathrm{x}}$ buffer and its thickness corresponds to the critical thickness of the graded $\mathrm{Si}_{1-\mathrm{x}} \mathrm{Ge}_{\mathrm{x}}$ alloy it consists of. This intermixing of the $\mathrm{V}$-Ge with the $\mathrm{Si}$ wafer is even better observed from the TEM image of the sample irradiated with 100 pulses, which again shows prominent strain fields on the Si substrate and the PLIE formed $\mathrm{Si}_{1-\mathrm{x}} \mathrm{Ge}_{\mathrm{x}}$ buffer (Fig. 4(c)). The alloyed region is now almost twice thicker and again good epitaxial
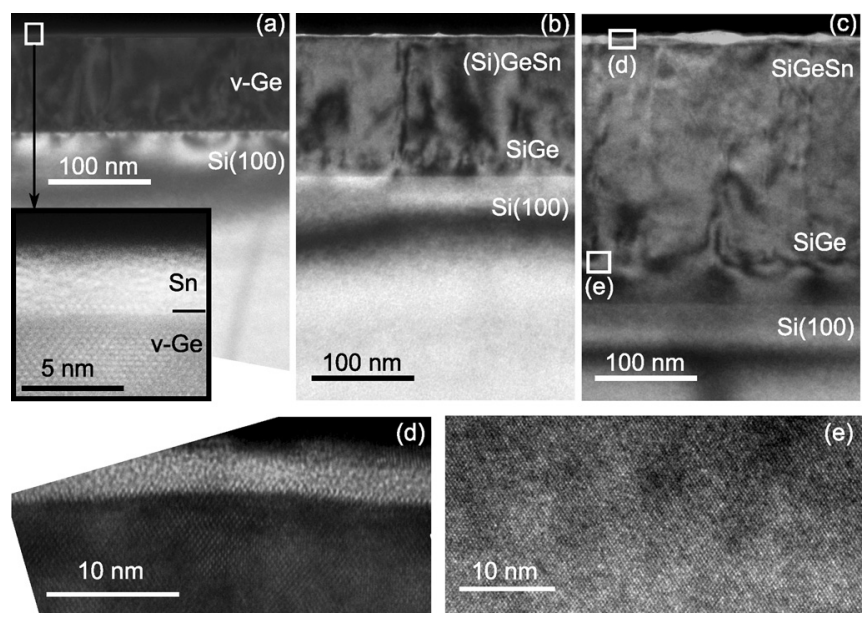

FIG. 4. TEM image of the "as grown" v-Ge/Sn (a) with magnified image of the Sn film (inset), the sample irradiated with 5 (b) and 100 (c) pulses. Magnified images close to the surface region (d) and at the strained buffer $\mathrm{Si}_{1-\mathrm{x}} \mathrm{Ge}_{\mathrm{x}}$ layer (e) for 100 pulse irradiation. quality can be seen, both for the $\mathrm{Si}_{1-\mathrm{x}} \mathrm{Ge}_{\mathrm{x}} / \mathrm{Si}_{1-\mathrm{x}-\mathrm{y}} \mathrm{Ge}_{\mathrm{x}} \mathrm{Sn}_{\mathrm{y}}$ on top (Fig. 4(d)) and the $\mathrm{Si}_{1-\mathrm{x}} \mathrm{Ge}_{\mathrm{x}}$ buffer (Fig. 4(e)).

For quantitative characterization of composition and quality assessment of the alloy obtained after 100 pulses, where the highest level of intermixing and smoothest gradients have been observed, RBS channeling using $1.4 \mathrm{MeV}$ $\mathrm{He}^{+}$ions at $170^{\circ}$ backscattering angle was performed. The simulation of the random spectrum indicates that the Sn containing part may be approximated by a layer system based on two $\mathrm{Si}_{1-\mathrm{x}-\mathrm{y}} \mathrm{Ge}_{\mathrm{x}} \mathrm{Sn}_{\mathrm{y}}$ films: a $50 \mathrm{~nm} \mathrm{Si}_{0.440} \mathrm{Ge}_{0.554} \mathrm{Sn}_{0.006}$ on top of a $50 \mathrm{~nm} \mathrm{Si}_{0.440} \mathrm{Ge}_{0.556} \mathrm{Sn}_{0.004}$, but assuming smearedout interfaces. For the $\mathrm{SiGe}$ region, multiple layers were used to simulate the gradient indicating that the alloy changes from $\mathrm{Si}_{0.445} \mathrm{Ge}_{0.555}$ on top to $\mathrm{Si}_{0.68} \mathrm{Ge}_{0.32}$ at the interface with the Si substrate. The minimum channeling yield, $\chi_{\text {min }}$, for the Sn channeling signal (inset of Fig. 5) is about $30 \%$ of the random spectrum, corresponding to a Sn substitutional incorporation of about $65 \%$. The channeling spectrum shows that the whole heterostructure is still epitaxial on the $\mathrm{Si}(100)$ substrate. In addition, the presence of an oxygen surface peak can be ascribed to oxidation of the stack surface.

In summary, pulsed lased induced epitaxy (PLIE) has been used to form $\mathrm{Ge}_{1-\mathrm{x}} \mathrm{Sn}_{\mathrm{x}} / \mathrm{Si}_{1-\mathrm{x}-\mathrm{y}} \mathrm{Ge}_{\mathrm{x}} \mathrm{Sn}_{\mathrm{y}}$ layers on $\mathrm{Si}$ with alloy composition that depends on the number of laser pulses. The typical drawbacks for traditional low temperature non-equilibrium epitaxial growth, such as formation of clusters, were not observed for PLIE. Substitutional Sn content of up to $0.6 \%$ in the top $50 \mathrm{~nm}$ of the $\mathrm{Si}_{0.440} \mathrm{Ge}_{0.554}$ buffer layer with decreasing Sn content in the next $50 \mathrm{~nm}$ was obtained after 100 pulses. This layer was followed by a $\mathrm{Si}_{1-\mathrm{x}} \mathrm{Ge}_{\mathrm{x}}$ layer with a slight gradient in composition. An intermediate case, where $\mathrm{Sn}$ and $\mathrm{Si}$ contents were graded in the top most layer, has also been observed and studied. Raman spectroscopy reveals the evolution of the level of intermixing between the three components and the transition from $\mathrm{Ge}_{1-\mathrm{x}} \mathrm{Sn}_{\mathrm{x}}$ to $\mathrm{Si}_{1-\mathrm{x}-\mathrm{y}} \mathrm{Ge}_{\mathrm{x}} \mathrm{Sn}_{\mathrm{y}}$ alloy with increasing number of pulses. "In situ" measured time resolved reflectivity was related to melting depth and duration, calculated using FEM

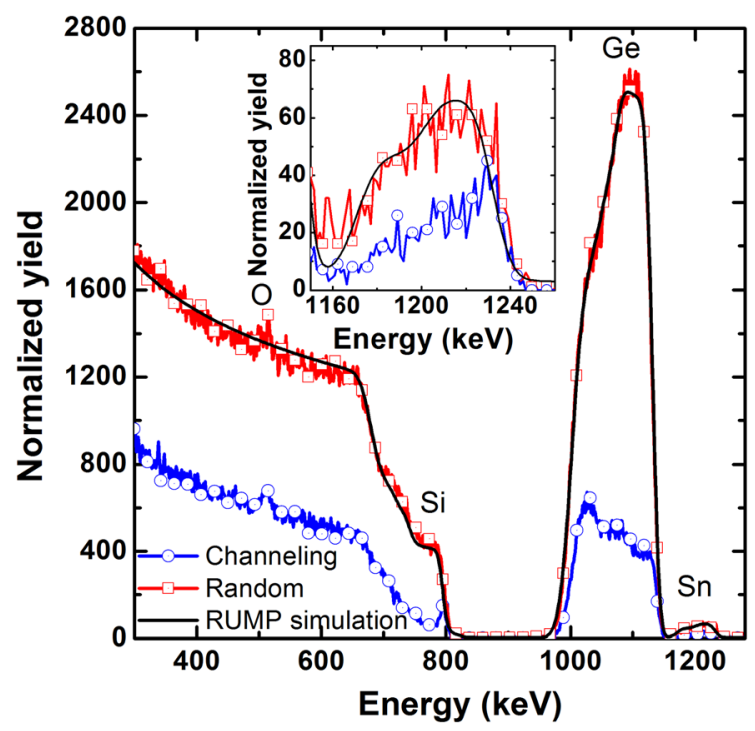

FIG. 5. Random (experimental data with simulation) and [001] channeling RBS spectra of a sample treated with 100 pulses of $500 \mathrm{~mJ} / \mathrm{cm}^{2}$. The inset shows a magnification of the backscattering signal of $\mathrm{Sn}$. 
solution of the HCDE for the 1st pulse of the applied experimental conditions.

Research on PLIE has been partially financed by Spanish (MAT2008-02350, MAT2011-24077) and Galician (2010/83) grants, co-financed by FEDER funds. Research at IHT was supported by the Deutsche Forschungsgemeinschaft (SCHU2496/4-1).

${ }^{1}$ D. W. Jenkins and J. D. Dow, Phys. Rev. B 36, 7994 (1987).

${ }^{2}$ P. Moontragoon, Z. Ikonic, and P. Harrison, Semicond. Sci. Technol. 22, 742 (2007)

${ }^{3}$ G. He and H. A. Atwater, Phys. Rev. Lett. 79, 1937 (1997).

${ }^{4}$ J. Kouvetakis, J. Menendez, and A. Chizmeshya, Annu. Rev. Mater. Res. 36, 497 (2006).

${ }^{5}$ J. Tolle, R. Roucka, A. V. G. Chizmeshya, J. Kouvetakis, V. R. D’Costa, and J. Menéndez, Appl. Phys. Lett. 88, 252112 (2006).

${ }^{6}$ R. Soref, J. Kouvetakis, J. Tolle, J. Menéndez, and V. D’Costa, J. Mater. Res. 22, 3281 (2007).

${ }^{7}$ E. Kasper, J. Werner, M. Oehme, S. Escoubas, N. Burle, and J. Schulze, Thin Solid Films 520, 3195 (2012).

${ }^{8}$ P. Aella, C. Cook, J. Tolle, S. Zollner, A. V. G. Chizmeshya, and J. Kouvetakis, Appl. Phys. Lett. 84, 888 (2004).

${ }^{9}$ J. Xie, A. V. G. Chizmeshya, J. Tolle, V. R. D'Costa, J. Menendez, and J. Kouvetakis, Chem. Mater. 22, 3779 (2010).

${ }^{10}$ G. H. Wang, E.-H. Toh, X. Wang, S. Tripathy, T. Osipowicz, T. K. Chan, K.-M. Hoe, S. Balakumar, G.-Q. Lo, G. Samudra, and Y.-C. Yeo, Appl. Phys. Lett. 91, 202105 (2007).
${ }^{11}$ C. D. Thurmond, F. A. Trumbore, and M. Kowalchik, J. Chem. Phys. 25, 799 (1956).

${ }^{12}$ S. Stefanov, J. C. Conde, A. Benedetti, C. Serra, J. Werner, M. Oehme, J. Schulze, and S. Chiussi, Thin Solid Films 520, 3262 (2012).

${ }^{13}$ S. Martelli, I. Vianey, R. Larciprete, E. Borsella, J. Castro, S. Chiussi, and B. León, J. Appl. Phys. 82, 147 (1997).

${ }^{14}$ N. Frangis, J. V. Landuyt, R. Larciprete, S. Martelli, E. Borsella, S. Chiussi, J. Castro, and B. León, Appl. Phys. Lett. 72, 2877 (1998).

${ }^{15}$ F. Liu, H.-S. Wong, K.-W. Ang, M. Zhu, X. Wang, D.-Y. Lai, P.-C. Lim, and Y.-C. Yeo, IEEE Electron Device Lett. 29, 885 (2008).

${ }^{16}$ S. Chiussi, F. Gontad, R. Rodríguez, C. Serra, J. Serra, B. León, T. Sulima, L. Höllt, and I. Eisele, Appl. Surf. Sci. 254, 6030 (2008).

${ }^{17}$ S. Stefanov, J. C. Conde, A. Benedetti, C. Serra, J. Werner, M. Oehme, J. Schulze, D. Buca, B. Hollaender, S. Mantl, and S. Chiussi, Appl. Phys. Lett. 100, 104101 (2012).

${ }^{18}$ J. Werner, M. Oehme, M. Schmid, M. Kaschel, A. Schirmer, E. Kasper, and J. Schulze, Appl. Phys. Lett. 98, 061108 (2011).

${ }^{19}$ H. Stöhr and W. Klemm, Z. Anorg. Allg. Chem. 241, 305 (1939).

${ }^{20}$ J. R. Abelson, T. W. Sigmon, K. B. Kim, and K. H. Weiner, Appl. Phys. Lett. 52, 230 (1988).

${ }^{21}$ G. E. Jellison, D. H. Lowndes, D. N. Mashburn, and R. F. Wood, Phys. Rev. B 34, 2407 (1986).

${ }^{22}$ J. C. Conde, E. Martín, S. Chiussi, F. Gontad, C. Serra, and P. González, Appl. Phys. Lett. 97, 014102 (2010).

${ }^{23}$ T. S. Perova, J. Wasyluk, K. Lyutovich, E. Kasper, M. Oehme, K. Rode, and A. Waldron, J. Appl. Phys. 109, 033502 (2011).

${ }^{24}$ V. D'Costa, J. Tolle, R. Roucka, C. Poweleit, J. Kouvetakis, and J. Menéndez, Solid State Commun. 144, 240 (2007).

${ }^{25}$ K. Uchinokura, T. Sekine, and E. Matsuura, J. Phys. Chem. Solids 35, 171 (1974). 